Behavior and Social Issues, 23, 52-67 (2014). (C) Lyle K. Grant. Readers of this article may copy it without the copyright owner's permission, if the author and publisher are acknowledged in the copy and the copy is used for educational, not-for-profit purposes. doi: 10.5210/bsi.v.23i0.5346

\title{
Insatiability: Part of the Problem or Part of the Solution?
}

\author{
Lyle K. Grant ${ }^{1}$ \\ Athabasca University
}

\begin{abstract}
Economic satiation is the idea that once people have attained an adequate level of income and consumption they reach a satiation point at which income and consumer goods become less effective as reinforcers and as sources of satisfaction. Advocates of a sustainable society have seen economic satiation as a natural method for reducing the overconsumption of goods and thereby producing environmental benefits including a reduction in carbon emissions and lessened demand for nonrenewable resources. Yet cross-cultural data from both developing and developed economies have been unable to fix a satiation point at which the reinforcing effectiveness of income declines. This finding of income insatiability is consistent with the status of money as a powerful generalized reinforcer that is not subject to satiation. A conceptual solution to the problem is to accept and even embrace the insatiability of generalized reinforcers, yet to develop a culture of education and skills that empowers alternative generalized reinforcers to the point at which their effectiveness rivals or exceeds that of income.
\end{abstract}

KEYWORDS: insatiability, satiation, satiation point, habituation, sustainability

As discussed in economics, satiation refers to a decrease in consumption of economic goods due to their repeated or prolonged use. The possibility of satiation to economic goods has assumed considerable importance in our era because it is a potential solution to the problems of global warming and resource depletion. In its report on climate change (Swim et al., 2010), the American Psychological Association's task force identified consumption, coupled with population growth, as an important driver of fossil-fuel use and global warming. Consumer products require the burning of fossil fuels for their manufacture and transport, so the onset of satiation to those products and the money used to purchase them would lessen material consumption and reduce fossil-fuel use.

Traditionally, within economics people are assumed to be insatiable consumers: Once one desire is satisfied, people are expected to move on to satisfy another one of a limitless pool of desires (Galbraith, 1998). A world of insatiable consumers pursuing economic goods on a planet of finite resources has been recognized as a fundamental problem (Brown, 2002; Engelbourg, 1963; Jackson, Jager, \& Stagl, 2004). Satiation has therefore been proposed as an ally of sustainability because it is a potential mechanism for reducing the satisfaction people receive from income and economic goods. Layard (2005) proposed that once people attain an income level at which their basic needs are satisfied, "additional income is not associated with extra happiness" (p. 33) and that "once subsistence income is guaranteed, making people happier is not easy." This possibility, the satiation-point hypothesis, offered a mechanism for helping to

\footnotetext{
${ }^{1}$ The author may be contacted at lyle@athabascau.ca
} 


\section{INSATIABILITY}

achieve a sustainable society because it means that people's motivation to obtain happiness through additional income and consumption declines once income is sufficient to meet basic needs.

Although some initial studies provided evidence for a satiation point for income, subsequent work (Sacks, Stevenson, \& Wolfers, 2012; Stevenson \& Wolfers, 2008; Stevenson \& Wolfers, 2013) failed to confirm such a point, dispelling any clear hope that people can and will automatically curtail their pursuit of income and consumption once their basic needs have been met. In the present article, I describe a conceptual means for reducing the demand for income and consumption by enhancing the effectiveness of competing sources of reinforcement rather than depending on the elusive effects of satiation.

The general purpose of the present article is to consider satiation from a behavioral perspective in order to clarify its role in contributing to sustainability. The status of satiation and insatiability is initially described as it exists within economics. The satiation-point hypothesis is described and its empirical status is reviewed. The notion of the generalized reinforcer is considered as the behavioral basis for insatiability, which discounts the satiation-point hypothesis. Important features of generalized reinforcers are described: They can be altered in their effectiveness and satiation-like decreases in their relative effectiveness can be achieved by setting up competing sources of reinforcement. Insatiability is reconsidered as desirable for both well-being and sustainability provided it applies to behavior maintained by resource-free and resource-light sources of satisfaction.

\section{Insatiability Versus the Satiation Point}

Satiation and its antithesis, insatiability, are concepts used in different ways in economics and in the other behavioral sciences. The central concern here is with one of those usages, the notion of satiation as attaining a state of economic satisfaction that reduces economic consumption, and insatiability as the failure of this process to occur. In The Affluent Society, economist John Kenneth Galbraith (1998) described this type of insatiability as occurring when "the urgency of wants does not diminish appreciably as more of them are satisfied" (p. 117). Galbraith acknowledged that economists have the view that:

When man has satisfied his physical needs, then insatiable psychologically grounded desires take over. These can never be satisfied, or, in any case, no progress can be proved. The concept of satiation has very little standing in economics. It is held to be neither useful nor scientific to speculate on the comparative cravings of the stomach and the mind. (p. 117)

Consistent with Galbraith's view, economic insatiability in the form of unlimited wants remains basic to economics and consumerism:

- "Economics examines how people use their scarce resources to satisfy their unlimited wants." (McEachern, 2012, p. 2).

- "Human needs are multifarious and unlimited" (Baillargeon, 2004, p. 4).

- "Individuals allocate their scarce resources among alternative uses so as to maximize their levels of lifetime satisfaction." (Bradfield, 2007, p. 3) 


\section{GRANT}

- "The concept of insatiability underlies the entire edifice of the consumer society" (Jackson et al., 2004).

Complete economic insatiability has not been universally accepted. Layard (2005) proposed that once income reaches a level of $\$ 20,000$ per capita, more income does not produce additional increases in happiness. This idea, the satiation-point hypothesis, is implicit as well in Galbraith's (1998) reference to the form of satiation that has "little standing" in economics: The idea that there is a point at which the "urgency of wants" does indeed diminish when more of them are satisfied.

The satiation-point hypothesis has important implications for sustainability. If it is true that there is a point at which increased income and material consumption fail to function as reinforcers and do not improve happiness or well-being, then this should act as a natural brake on consumption. $^{2}$ Diminished consumption would in turn reduce manufacturing activity, lessen carbon emissions, and reduce the demand for finite natural resources, preserving a supply for future generations. In addition, if people were satiated with income, this could reduce the amount of time they spend working, which would also contribute to sustainability (Coote \& Franklin, 2013; Hayden, 1999; Knight, Rosa, \& Schor, 2013).

Some have agreed that there is an income satiation point (e.g., Ahuvia, 2008; Durning, 1992; Etzioni, 2009b; Wilkinson \& Pickett, 2010), but then a problem becomes explaining why people continue to seek income and consumer goods beyond the satiation point instead of cutting back their working hours. One explanation is that people "are hoodwinked by a consumerist culture" in attempts "to satisfy with material things what are essentially social, psychological, and spiritual needs" (Durning, 1992, p. 23). Ahuvia (2008) attributes the problem to several factors, including (a) failures to set happiness as a life goal, (b) excessive influence by the short-term rewards that income provides, and (c) evolved biological tendencies to store resources, making oneself sexually attractive, and to attain high relative social status. Wilkinson and Pickett (2010) also connect well-being to relative social status, maintaining that economic inequality impairs well-being, for example by increasing anxiety due to social comparisons. Their findings led them to state that "reducing inequality would increase the wellbeing and quality of life for all of us" (p. 33), a conclusion Stiglitz (2012) also reached. Common to all these perspectives is the notion that beyond the income satiation point, people are motivated by favorable relative social comparisons and higher relative income, but these motives fail to pay off in improved happiness and well-being, an ultimately more important outcome.

\footnotetext{
${ }^{2}$ Some economists have come to make use of measures of subjective well-being and happiness, which is an improvement on the traditional practice of assuming for example that GDP growth automatically enhances wellbeing (Anielski, 2007). Behavior analysts consider happiness to be "a feeling, a by-product of operant reinforcement" (Skinner, 1974, p.70) that is important. Yet at the same time, behavior analysts are also wary or an excessive focus on feelings because doing so "obscures the realization that "The things which make us happy are the things which reinforce us". Further, "it is the things, not the feelings, which must be identified and used in prediction, control and interpretation. Consistent with this view, beginning with Wolf (1978), behavior analysts have also come to use measures of subjective well-being to corroborate the beneficial effects of behavioral procedures, which is described in terms of the social validity of those procedures. In those terms, this article is concerned with the social validity of money and alternative generalized reinforcers.
} 


\section{INSATIABILITY}

\section{Empirical Evaluations of the Satiation Point}

Early research appeared to support the existence of an economic satiation point. When selfrated well-being was plotted for individual countries differing in income per capita, it appeared that at the low end of the income spectrum, well-being increased substantially with income, but at the high end of the income scale, well-being increased little or not at all with more income. In commenting on these findings, Layard (2003) initially pegged the satiation point at $\$ 15,000$ per capita, a figure he later elevated to $\$ 20,000$ :

... once a country has over $\$ 15,000$ per head, its level of happiness appears to be independent of its income per head. For poorer countries, however, there is a clear impact of income on happiness, which is also borne out by the time-series in India, Mexico and the Philippines. When you are near the bread-line, income really does matter. (p. 17)

Yet working with very large international data sets, Stevenson and Wolfers (2008) examined income and self-rated subjective well-being and found a consistently positive relationship between the two throughout the income scale. Greater income was associated with greater wellbeing both within individual countries and across rich and poor countries. Regarding satiation, they wrote:

There appears to be a very strong relationship between subjective well-being and income, which holds for both rich and poor countries, falsifying earlier claims of a satiation point at which higher GDP per capita is not associated with greater well-being. (p. 3)

Stephenson and Wolfers' data showed a linear relationship between log-scaled income and self-rated well-being. Using log-scaled income enabled a comparison of the relative contribution of the same percentage rise in income on well-being. Because incomes in poor countries are low, a relatively small dollar increment in income has a much greater impact on well-being in poor countries than it has in wealthy nations. For example:

GDP per capita in Burundi is about one-sixtieth that in the United States; hence a $\$ 100$ rise in average income would have a twenty-fold larger impact on measured well-being in Burundi than in the United States. (p. 23)

They further point out that when subjective well-being is plotted as a function of absolute income:

...the subjective well-being-income gradient is curvilinear and thus is less steep among wealthier countries. Although the slope is never zero, the flattening out of the curve may be more easily misinterpreted as satiation. (p. 23)

In other words, as long as income continues to rise at a given percentage, self-rated well-being will correspondingly rise, even when incomes in absolute dollar figures reach huge sums.

Stevenson and Wolfer's findings have attracted attention because it applies to the oftenasked question of whether money can buy happiness. The results of the study were widely reported in articles and blogs entitled "Maybe Money Does Buy Happiness After All" (Leonhardt, 2008) in The New York Times, "It Turns Out Money Can Buy Happiness" (Munoz, 2008) in The Wall Street Journal, and "Yes, Money Really Can Buy Happiness" (Matthews, 
2013) in The Washington Post. The New York Times article quoted Nobel-prize winning psychologist Daniel Kahneman, who had previously questioned a strong link between income and happiness. Kahneman found Stevenson and Wolfer's data "quite compelling" (Leonhardt, 2008, $\mathbb{P}$ 15). Another prominent economist, Robert Frank (2012), who has recognized the problem of excessive consumption and proposed a tax system to address it, also accepted the positive relationship between absolute income and well-being. The absence of a satiation point was reaffirmed in more recent work (Sacks et al., 2012; Stevenson \& Wolfers, 2013). Although important details remain to be better understood, the data show little evidence of an income satiation point.

\section{Generalized Reinforcement and Insatiability}

The apparent absence of an income satiation point is ostensibly bad news for achieving a sustainable society. Money remains effective as a reinforcer throughout the income scale and therefore there is no clear income satiation point. Those high on the income scale have a higher savings rate (Dynan, Skinner, \& Zeldes, 2004), so it might be suggested that income transformed into savings is not harmful because it entails no consumption. Savings are nonetheless a claim on future consumption and savings are typically invested in enterprises that facilitate and promote consumption in order to maximize return on investment.

Satiation is a passive process because the reduction of consumption occurs without anything more than consumption reaching a given level. A key implication of the absence of a satiation point for income is that the behavioral process of satiation, which occurs automatically as consumption occurs, cannot be relied upon as a means of reducing people's motivation to seek money. To reduce consumption, we must turn to invoking active behavioral processes concerned with competition among reinforcers, which necessitates an understanding of generalized reinforcers.

Behavior analysts make a distinction between unconditioned and conditioned reinforcers. Unconditioned reinforcers have acquired their ability to reinforce due to the history of the species: Food, water, oxygen, relief from pain, a comfortable temperature, and sexual contact for example are all examples of unconditioned reinforcers. Such reinforcers are established through a process of biological evolution that has selected organisms who were more likely to survive if they were susceptible to these unconditioned reinforcers. Galbraith (1998), as quoted earlier, referred to our finite "physical needs", which are needs capable of being satiated by unconditioned reinforcers. In contrast, conditioned reinforcers acquire their ability to reinforce due to learned associations with other reinforcers during our lifetimes. Money for example has little effect on the behavior of infants, but because money is differentially associated with other reinforcers during childhood, it acquires considerable reinforcing effectiveness.

Unlike unconditioned reinforcers that are finite in number, conditioned reinforcers are potentially unlimited, but their effectiveness depends on a process of differential association that establishes their effectiveness (Cairns, 1967, 1970; Cairns \& Paris, 1971; Lovaas et al., 1966; Warren \& Cairns, 1972). For example a child brought up in a home that values the pleasures of warm personal relationships, reading, mathematics, amateur science, painting, soccer, etc., will tend to acquire these conditioned reinforcers, whereas children brought up in a home that values opulent material objects will acquire those conditioned reinforcers (Goldberg, Gorn, Peracchio, \& Bamossy, 2003; Lekes et al., 2011). 


\section{INSATIABILITY}

Generalized conditioned reinforcers (or simply generalized reinforcers) are effective as reinforcers independently of any specific state of deprivation. Money is an example of a generalized reinforcer. Money functions a reinforcer whether or not we are hungry, thirsty, cold, etc. because it can be exchanged for a large variety of unconditioned and other conditioned reinforcers. The effectiveness of generalized reinforcers at least initially depends on the extent of the variety of reinforcers that have been differentially associated with the generalized reinforcer. Moher, Gould, Hegg, and Mahoney (2008) examined the establishment of a generalized conditioned reinforcer, a token, by pairing the tokens (e.g., poker chips or blue beads) with different back-up reinforcers. They found that the more backup reinforcers the token was paired with, the less effect a satiation procedure had on the reinforcing effectiveness of the tokens. A generalized reinforcer like money has been associated with so many different reinforcers for such a long period that the conditions that established money as a reinforcer are usually a forgotten part of the past. By using tokens, Moher et al. (2008) were able to examine the establishment of a generalized reinforcer and show the importance of a variety of backup reinforcers in that process.

Skinner (1953) discussed several other generalized reinforcers apart from money: Attention, affection, approval, autonomy (i.e., "having one's own way", p. 79), and "control of the physical world" (p. 77), a generalized reinforcer that "may explain our tendency to engage in skilled crafts, in artistic creation, and in such sports as bowling, billiards, and tennis." (p. 77). Similarly, reading for pleasure, artistic appreciation, and watching sporting events are also generalized reinforcers because they too are effective independently of any state of deprivation. Skinner further suggested that generalized reinforcers become effective "even though the primary reinforcers upon which they are based no longer accompany them. We play games of skill for their own sake. We get attention or approval for its own sake." (p. 81)

Generalized reinforcers provide a behavioral basis for insatiability because once a generalized reinforcer is established, it is effective, potentially infinitely, under a wide variety of conditions and independently of any specific biological needs. Insatiable desires for money and income, for example, are rooted in money's status as a generalized reinforcer that frequently, clearly, and quantitatively signals the availability of a wide variety of other reinforcers. Money can also be stored for future use and retains a precise numerically scaled exchange value. These features of money led Alhadeff (1982) to conclude that "the reinforcement-effectiveness limit for money is indeterminate both in principle and in practice. As a practical matter, the possibility of such a limit for money can be ignored; and the same conclusion holds for financial assets." (p. 155). Alhadeff defined a reinforcer effectiveness limit as "the point at which a given commodity ceases to be a reinforcer" (p. 60). In other words, as a reinforcer money has no satiation point at which it no longer functions as a reinforcer provided it continues to be signal the availability of other reinforcers in standard everyday purchases and retains its stored value. Exceptions to this can include instances in which frequent reassociation is prevented or limited, for example as in the case of the former Soviet Union's constraints on the exchangeability of the ruble or cases in which extreme inflation prevents money from retaining its stored value.

The absence of a satiation point for money also applies in principle and in practice to other generalized reinforcers. Past instances of praise, recognition, and adulation do not accumulate to a point at which future instances no longer function as reinforcers, provided that the instances reliably signal the availability of other reinforcers. Likewise, past instances of reinforcement due to reading or writing a good book, creating an attractive painting, creating open-source software, socializing with family and friends do not accumulate to a point at which these activities cease to 
be reinforcers or are permanently weakened as reinforcers. The effectiveness of these generalized reinforcers is also refreshed in part by participation in a supportive community that recognizes and reinforces improvements and achievements in these domains. For example, bohemian communities have historically provided social support for nascent artists and writers who would otherwise go ignored within mainstream culture (de Botton, 2004; Grant, 2010). These subcommunities offer a set of local interlocking practices (Glenn \& Malagodi, 1991) that support behaviors that mainstream culture ignores or discourages. Because generalized reinforcers are not subject to long-term satiation, greater amounts will generally produce more reinforcement and more subjectively perceived satisfaction. Other sources of reinforcement being equal, more income will generally be more reinforcing, but this also applies to other generalized reinforcers: Everything else being equal, more praise, recognition, captivating books read, and good music enjoyed will yield greater reinforcement and satisfaction. If you are a skilled artist or writer, creative output will be reinforcing, but so generally will additional income.

Simply accepting that money is an effective reinforcer at all points in the income scale does not carry with it larger implications that for example money is the litmus test of personal success, that wealth and consumption must define personal identity, or that a large income is essential to well being. Success and identity are social constructions that can be redefined within subcultures. Yet historically the approach of entirely disavowing money as reinforcer or source or satisfaction, as seen in extreme bohemian subcultures, ends in an inability to negotiate the practical realities of subsistence, often with tragic results (Etzioni, 2009a; Wetzsteon, 2002). In contrast, the contemporary voluntary simplicity movement (Elgin, 1993) operates on the premise that attention to money management is essential to enjoying a life of intentionally diminished material consumption (Dominguez \& Robin, 1992).

Our overall time is limited in daily life and therefore different sources of reinforcement compete for how we allocate our time, as emphasized in work with response hierarchies (Premack, 1959; Bernstein \& Ebbesen, 1978). A day can include work maintained by income, meals maintained by food, family time maintained by social reinforcement, pleasure reading maintained by literary reinforcers, etc. A general principle is that the amount of time spent on different activities will be proportional to the relative reinforcement received for those activities (Herrnstein, 1970). A universe of multiple behaviors complicates a simple analysis in terms of satiation. Is a worker who forgoes overtime pay to go fishing satiated with income or deprived of the reinforcers inherent in enjoyment of the outdoors? Does retiring early to paint landscapes mean one is satiated with income or that a confluence of life circumstances have boosted the satisfactions of painting relative to paid work? In a multiple activity context, describing reduction in a response in terms of satiation or a satiation point inappropriately narrows the focus on an individual behavior rather than all the conditions that contribute to the relative probability of activities that compete for our time.

Understanding the effects of competition among generalized reinforcers provides a means of achieving sustainability. Income is one of many potentially powerful generalized reinforcers, which include those inherent in the arts, much of science, open-source computing, sports, conversation, family relationships, games of skill, and a range of other skill sets, sometimes described as serious leisure (Stebbins, 2007), which do not typically require intensive fossil-fuel and other natural-resource inputs. These reinforcers are cost-efficient because the reinforcement 


\section{INSATIABILITY}

they provide per unit of dollar cost is high. ${ }^{3}$ Moreover, as Scitovsky $(1977,1989 \mathrm{~b}, 1992)$ pointed out in his work, as people acquire increasingly advanced skill sets, this enriches and differentiates their available reinforcers. Progressive advancements in skill in the arts, in sports, in conversation, in reading, etc. are matched by progressive increases in reinforcement, partially due to the creation of pleasing forms of novelty. Learning to draw is an example: As you become more adept at drawing, the novel forms you produce, which are potentially infinite, become progressively more aesthetically pleasing, both to the artist and onlookers, as new subskills are learned. Open-source computing is another example. I am writing this on a computer that uses the Debian Linux operating system, the Fluxbox window manager, and the Libreoffice word processor. The programmers who developed and maintain these tools elected to spend their spare time developing free open-source software rather than working for money. For a skilled programmer, producing clean, creative, and competent working code is powerful source of reinforcement, augmented by peer recognition forthcoming from open-source programming communities (Lakhani \& Wolf, 2005). If money and income were omnipotent sources of reinforcement, open-source software and operating systems would not be able to compete as they have with highly capitalized corporations. By 2009, the CEO of Microsoft had come regard the open-source Linux operating system as a bigger competitor than the next-largest corporate operating system from Apple Computer (Holwerda, 2009).

A psychological key to sustainability therefore becomes creating and maintaining the effectiveness of generalized reinforcers capable of competing with income for people's time and interest. Because the motivation to obtain income is insatiable, the appropriate macro strategy becomes not satiation but the differential reinforcement of incompatible behavior (DRI) (Martin \& Pear, 2011), which sets up reinforcer competition. Etzioni (2009b) highlighted the necessity of DRI contingencies:

A culture in which the urge to consume dominates the psychology of citizens is a culture in which people will do most anything to acquire the means to consume - working slavish hours, behaving rapaciously in their business pursuits, and even bending the rules in order to maximize their earnings. ...But it is not enough to establish that which people ought not to do, to end the obsession with making and consuming evermore than the next person. Consumerism will not magically disappear from its central place in our culture. It needs to be supplanted by something. (p. 20)

As for the something, Etzioni (2009a) raised the possibility of a culture in which knowledgebased and relationship-based sources of satisfaction supplant material consumption. Etzioni cited examples of knowledge-based objects including Beethoven symphonies, popular music, Shakespeare's plays, and Kafka's stories. Due to digitization, Internet availability, and copyright expirations, these objects are increasingly available on a resource-free or resource-light basis and can be repeatedly consumed by millions of people without impairing their continued reuse. He

\footnotetext{
${ }^{3}$ Reinforcer cost efficiency (RCE) is the ratio of the effectiveness of a source of reinforcement divided by its unit cost. RCE is a measure of how much behavior can be maintained, and how much associated well-being can be obtained from different reinforcers which differ in dollar costs. RCE provides one measure of sustainability because it measures reinforcer effectiveness relative to dollar costs and the associated resource demands. For example, reading a good library book has a high RCE because it strongly maintains behavior at low dollar costs, whereas watching commercial TV has a lower RCE because it maintains behavior while the consumer's behavior is being conditioned through advertising to make future purchases.
} 
contrasts these objects with that of a Porsche manufactured using a large quantity of energy and other resources, yet is usable only by the vehicle's owners and "once 'consumed', little value remains" (p. 67). Relationship-based sources of satisfaction include "bonding, love, intimacy, friendship, contemplation, communion with nature," "volunteering, national service, and politics", all of which "can free one, to a large extent, from key laws of capitalist economies" ( $p$. 68). In more technical terms, building a sustainable society therefore depends on the extent to which we can elevate the reinforcing effectiveness of knowledge-based and relationship-based outcomes over material goods, as a wide variety of alternative-culture theorists have proposed (Csikszentmihalyi, 1999; Mill, 1848; Russell, 1935; Schaefer, 2008; Scitovsky, 1989a; Skinner, 1976; Thoreau, 1854/1995).

Setting up competing sources of reinforcement from knowledge-based and relationshipbased objects is more difficult than satiation, which occurs automatically as a result of consumption. In order to acquire learned reinforcers, learned sources of satisfaction, a formal or informal learning process must take place that boost the level of satisfaction we receive from knowledge-based and relationship-based sources relative to income and ensuing consumption. Education and learning therefore assume overwhelming importance.

\section{Conceptual and Practical Implications}

Progress toward a sustainable culture requires both conceptual and practical changes. On a conceptual level, economics requires (a) an understanding of the characteristics of generalized reinforcers, (b) a recognition that the relative effectiveness of all reinforcers can be systematically altered through the use of motivating operations (Michael, 2004), and (c) that reinforcer competition rather than income satiation is essential to encouraging forms of behavior that require less material consumption. Once economists and those who formulate public policy understand these features of human behavior our society will be better positioned to seek behavioral solutions to the problems of excess material consumption and move toward a sustainable society.

The aggregate data showing a positive relationship between increased income and increased satisfaction does not necessarily mean that people are relegated to exist in an economic monoculture (Michaels, 2011) in which everyone's well being depends on maximization of income irrespective of how this impairs sustainability and a balanced life. Society as a whole as well as individuals acting on their own have the ability to create reinforcers and alter their effectiveness. On a practical level, a sustainable culture requires procedures to diminish the relative effectiveness of income and consumer goods and educational and other reforms designed to elevate the relative effectiveness of reinforcement cost-efficient activities. There is no satiation point for income and wealth, but our current corporate-dominated culture boosts their effectiveness with methods such as advertising. These methods synthetically make consumer goods more attractive than they would otherwise be, for example by Pavlovian conditioning techniques that link purchased material goods to cost-free pleasures such as sensuality, pleasing music, warm social relationships (O'Barr, 2006). In this sense people are hoodwinked by consumer culture, as Durning (1992) asserted. Taxing advertising would therefore have a positive influence on sustainability by reducing the artificially created demand for income and consumer products (Sanne, 2002). Similarly, a consumption tax proposed by Frank (1999) would have the same influence due to response-cost procedures, in behavioral terms. 


\section{INSATIABILITY}

People can also be encouraged to engage in reinforcer cost-efficient behaviors by increasing their reinforcing effectiveness relative to behaviors that are reinforcement cost-inefficient. Education is crucial in achieving this because many reinforcer cost-efficient activities require a relatively long learning period before the applicable reinforcers became fully effective (Scitovsky, 1992). Playing chess or bridge for example can provide considerable satisfaction, but mastery of their complexities occurs only after months and years of learning. Economics proceeds with the assumption of consumer sovereignty, the idea that consumer preferences determine what goods and services (i.e., reinforcers) are produced. However, if consumers lack the skills needed to enjoy particular rewards, such as chess, serious literature, the natural environment, musical performance, etc., then their preferences will be restricted to those that require relatively trivial skills, such as much of televised entertainment, shopping, adoration of wealthy celebrities, and material consumption, all of which fuel the unsustainable use of resources directly or indirectly (Scitovsky, 1992).

Although education is central to providing people with the skills needed to enjoy a sustainable mode of living, educators often fail to see their role as teaching students to enjoy what they learn. From the early grades onward education has been mainly concerned with teaching income-generating skills in order to maximize income and economic growth rather than "the skills that merely make life meaningful and worth living" (Scitovsky, 1992, p. 301). Scitovsky further maintained that due to the void created by the lack of skills that produce pleasure and enjoyment, young people turn to "the excitement of violence and drugs" which "crowd out the excitement and enjoyment that art and culture have to offer" (p. 301). Our educational system proceeds with the contractual assumption that if students learn well, they will later be rewarded with deferred employment, compensation, and material consumption, so the creation of immediate, intrinsic, and natural reinforcers need not be a concern. On a system-wide basis, it is unimportant whether the students enjoy what they are learning as long as they become proficient, gain marketable skills, and boost the economy. This deferred-and-extrinsic compensation model of education is wholly inappropriate for teaching sustainable, reinforcement cost-efficient skills that are maintained over our lifetimes by the nature of the activities themselves, as in the case of the arts, music, sports, games, open-source computing, etc. In these fields a successful education demands that students come to value and enjoy the activities themselves and to choose them over remunerated work. Attempts to impart values in the form of strong affinities for what is learned have largely been ignored in education (Pierre \& Oughton, 2007). One significant effort to address the issue of the affective domain in education (Krathwohl, Bloom, \& Masia, 1964), "was never taken seriously, either by educators or governments" (Lynch, 2010, p. 61).

Education to build a sustainable society must therefore focus on elevating the effectiveness of reinforcers that are intrinsic to sustainable behaviors. Skinner (Evans, 1981) advocated this nonstandard approach to education in a widely cited quote: "We shouldn't teach great books; we should teach a love of reading. Knowing the contents of a few works of literature is a trivial achievement. Being inclined to go on reading is a great achievement." (p. 73) Skinner regarded teaching a love of reading as a procedural matter of increasing the effectiveness of reading as a reinforcer by "scheduling reading material so that the student is reinforced at the right time" permitting the student to "go on reading more and more difficult things and continue to read throughout his life." (p. 73).

Addressing sustainability is within the reach of individuals: "Through control of the setting conditions of our moment-to-moment personal environments and interlocking them with 
contingencies maintained by a community of supporters, striking changes in our personal rates of consumption can happen" (Bostow, 2011, p 279). The intergenerational transfer of values occurs naturally within families, where "a favorable family background enables some people to acquire certain consumption skills effortlessly ...The children of bookish parents often acquire a literary taste with no visible effort." (Scitovsky, 1992, p. 227). Individuals interested in leading alternative lives in the arts, literature, and other sustainable pursuits have historically done so by affiliating themselves in supportive subcultures, which can include bohemian societies (de Botton, 2004; Grant, 2010). Other microenvironments such as those that compose structured voluntary activities (Larson, 2000), intentional communities (Sanguinetti, 2012), and cooperatives (Alavosius \& Newsome, 2012) all provide a means of transmitting and maintaining alternative value systems. For example, "...cohousing residents benefit from a sense of belonging, self-esteem, social support, living with people with similar interests, and sharing expertise" (Sanguinetti, 2012, p. 11). Similarly, economic cooperatives "by design, align individual actions with the commonwealth" (Alavosius \& Newsome, 2012, p.78) and foster adoption of a common set of intrinsic values. These subcultural communities are for example important in providing praise and recognition, which are important in the development of the intrinsic reinforcers (Cameron, Banko, \& Pierce, 2001; Cameron \& Pierce, 1994).

At the same time, it is important to recognize that both people in underdeveloped cultures and the poor in developed economies need increased income to provide for necessities. These considerations underscore the importance of increasing economic equality, both within developed economies and between developed and underdeveloped economies (Stiglitz, 2012, Wilkinson \& Pickett, 2010). Poor people in any society are compelled to allocate their time and energy to securing necessities, making it impossible for them to experience any reinforcing alternatives to income. In contrast, economic equality lays the foundation for a sustainable society by giving people sufficient income to acquire tastes for knowledge-based and relationship-based sources of satisfaction.

\section{Insatiability Reconsidered}

As we have seen, discussions of insatiability frequently assert that people are inherently insatiable, which is an example of essentialism, of attributing behavior to inherent properties (Palmer \& Donahoe, 1992). Insatiability is better seen as a feature of behavior due to a learning history with generalized reinforcers within our cultural context. Within contemporary consumer culture, a variety of conditions including the market economy, the rise of corporate power (Korten, 2001), government policy (Collins, 2000), innovative products, advertising, and social comparison processes (Frank, 1999) have functioned to create insatiable demand for consumer goods, yet before the rise of consumer culture people accepted sufficiency as a way of life, not constantly aspiring to consume more (Brown, 2002; Shi, 1985; Stearns, 2006).

Efforts aimed at curtailing insatiability are unlikely to succeed because they challenge and threaten people's sources of satisfaction. An approach with better prospects, at least in the medium- to long-term, is to alter what motivates people and reinforces their behavior. This approach goes neglected for several reasons, one of which is the absence of a systematic approach to the conditions that elevate and reduce reinforcer effectiveness (Michael, 2004), something that is relatively well advanced only within the discipline of behavior analysis. 


\section{INSATIABILITY}

Traditionally economics has assumed that people's values and preferences are "exogenous to the economic system, and that the economic problem consists of optimally satisfying those preferences" (Norton, Costanza \& Bishop, 1998, p. 193). Addressing the problems of sustainability requires that we reconceptualize values and preferences as alterable and treat them in terms of reinforcer effectiveness, a variable quantity, rather than as fixed entities. In a promising development, some economists have come to recognize the role of learning in the acquisition and alteration of values (Norton et al., 1998; Stiglitz, 2010).

Discussions of insatiability often portray it as incompatible with sustainability (Brown, 2002; Engelbourg, 1963). A growing population of insatiable consumers places demands on natural resources, eventually creating scarcities that threaten well being, potentially catastrophically. Yet insatiability for nonmaterial satisfactions is an ally of sustainability and a worthy characteristic that encourages personal growth and enriches human experience. As discussed earlier, Galbraith (1998) portrayed economics as assuming that insatiable "psychologically grounded desires" take over once biological needs are satisfied. The emergence of insatiable psychological desires can be either beneficial or harmful depending on which desires are strongest, on which reinforcers are most effective. Students who have insatiable quest for knowledge, lovers who have insatiable desires for each other, parents who insatiably strive to prepare their children to enjoy life, athletes who have an insatiable motivation to excel, scientists who are insatiably curious, and artists and writers who insatiably explore aesthetic and literary frontiers are all role models for a sustainable culture. These resource-free and resource-light forms of insatiability are generally considered desirable as long as they compose a part of a larger balanced mode of living in which different forms of worthy insatiable and satiable motivations coexist, enabling the individual to negotiate daily life pragmatically, successfully, and sustainably. In contrast, low motivation due to the lack of effective reinforcers has been implicated in the pathology of clinical depression (Lewinsohn, 1974; Kanter et al., 2010). In their review of behavioral activation treatments for depression Kanter et al. highlighted "the importance of natural and stable sources of positive reinforcement for a healthy, non-depressed lifestyle" (p. 617). More broadly, insatiable motivation due to effective reinforcers can be regarded as the basis of passion and zest (Peterson, Park, Hall, \& Seligman, 2009; Russell, 1930), perseverance (Duckworth, Peterson, Matthews, \& Kelly, 2007; Shechtman, DeBarger, Dornsife, Rosier, \& Yarnell, 2013), and task centeredness (Csikszentmihalyi, 1990).

Desirable forms of insatiability should be regarded as ideals in which powerful and neverending sources of environmentally sustainable satisfaction are forthcoming. Yet modern economic, governmental, and educational institutions, as well as popular culture, are all skewed to promote forms of insatiability consisting of motivation to secure money and consumer products. Schor (1992), Putnam (2000), McKibben (2007), and Michaels (2011) have all documented how during the past several decades this form of insatiability has taken everincreasing precedence over knowledge-based, relationship-based, resource-free, and resourcelight sources of sustainable satisfaction.

A world of insatiable people is one in which people are active, have passionate interests, and look forward to the consequences of their own behavior. If the reinforcers people seek are sustainable and sufficiently effective, people will have potentially unlimited sources of satisfaction in their lives. Yet in our current cultural milieu, we regard insatiability with trepidation, which itself reflects the way in which the culture, even apart from the discipline of economics, has narrowly equated strong motivation with material consumption. Insatiability is at once at the core of the problem and at the heart of the solution. 


\section{GRANT}

\section{References}

Ahuvia, A. (2008). If money doesn't make us happy, why do we act as if it does? Journal of Economic Psychology, 28, 491-507. http://dx.doi.org/10.1016/j.joep.2007.11.005

Alavosius, M. D., \& Newsome, W. D. (2012). Cooperatives, green behavior, and environmental protection. Revista Latinoamericana de Psicología, 44, 77-85.

Alhadeff, D. A. (1982). Microeconomics and human behavior: Toward a new synthesis of economics and psychology. Berkeley, CA: University of California Press.

Anielski, M. (2007). The economics of happiness: Building genuine wealth. Gabriola Island, British Columbia, Canada: New Society Publishers.

Baillargeon, J. (2004). Market and society: An introduction to economics. Halifax, Canada: Fernwood.

Bernstein, D. J., \& Ebbesen, E. B. (1978). Reinforcement and substitution in humans: A multiple response analysis. Journal of the Experimental Analysis of Behavior, 30, 243-253. http://dx.doi.org/10.1901/jeab.1978.30-243

Bostow, D. E. (2011). The personal life of the behavior analyst. The Behavior Analyst, 34, 267-282.

Bradfield, J. (2007). Introduction to the economics of financial markets. New York: Oxford University Press.

Brown, D. (2002). Insatiable is not sustainable. Westport, CN: Praeger.

Cairns, R. B. (1967). The information properties of verbal and nonverbal events. Journal of Personality and Social Psychology, 5, 353-357. http://dx.doi.org/10.1037/h0024296

Cairns, R. B. (1970). Meaning and attention as determinants of social reinforcer effectiveness. Child Development, 41, 1067-1082. http://dx.doi.org/10.2307/1127333

Cairns, R. B., \& Paris, S. G. (1971). Informational determinants of social reinforcement effectiveness among retarded children. American Journal of Mental Deficiency, 76, 362-369.

Cameron, J., Banko, K. M., \& Pierce, W. D. (2001). Pervasive negative effects of rewards on intrinsic motivation: The myth continues. The Behavior Analyst, 24, 1-44.

Cameron, J., \& Pierce, W. D. (1994). Reinforcement, reward and intrinsic motivation: A meta-analysis. Review of Educational Research, 64, 363-423. http://dx.doi.org/10.3102/00346543064003363

Collins, R. M. (2000). More: The politics of economic growth in postwar America. Oxford: Oxford University Press.

Coote, A., \& Franklin, J. (Eds.) (2013). Time on our side: Why we all need a shorter working week. London, UK: New Economics Foundation.

Csikszentmihalyi, M. (1990). Flow: The psychology of optimal experience. New York: Harper \& Row.

Csikszentmihalyi, M. (1999). If we are so rich, why aren't we happy? American Psychologist, 54, 821-827. http://dx.doi.org/10.1037/0003-066X.54.10.821

de Botton, A. (2004). Status anxiety. New York: Pantheon.

Dominguez, J., \& Robin, V. (1992). Your money or your life: Transforming your relationship with money and achieving financial independence. New York: Penguin.

Duckworth, A. L., Peterson, C., Matthews, M. D., \& Kelly, D. R. (2007). Grit: perseverance and passion for longterm goals. Journal of Personality and Social Psychology, 92, 1087-1101. http://dx.doi.org/10.1037/00223514.92.6.1087

Durning, A. T. (1992). How much is enough: The consumer society and the future of the Earth. New York: W.W Norton.

Dynan, K. E., Skinner, J., \& Zeldes, S. P. (2004). Do the rich save more? Journal of Political Economy, 112, 397444. http://dx.doi.org/10.1086/381475

Elgin, D. (1993). Voluntary simplicity : Toward a way of life that is outwardly simple, inwardly rich. New York: Morrow.

Engelbourg, S. (1963). Insatiability, a problem for utopia?. American Journal of Economics and Sociology, 22, 129140. http://dx.doi.org/10.1111/j.1536-7150.1963.tb00869.x

Etzioni, A. (2009a). A new social movement? In S. Alexander (Ed.), Voluntary simplicity: The poetic alternative to consumer culture (pp. 55-73). Whanganui, New Zealand: Stead \& Daughters. Retrieved from http://www.gwu.edu/ ccps/etzioni/documents/A403\%20A\%20New\%20Social\%20Movement.pdf.

Etzioni, A. (2009b). Spent: America after consumerism. The New Republic, 240(10), 20-23. Retrieved from http://www.gwu.edu/ ccps/etzioni/documents/B508\%20Spent,\%20America\%20after\%20consumerism.pdf.

Evans, R. I. (1981). Dialogue with B. F. Skinner. New York: Praeger.

Frank, R. H. (1999). Luxury fever: Money and happiness in an era of excess. Princeton, NJ: Princeton University Press.

Frank, R. H. (2012). The Easterlin Paradox revisited. Emotion, 12, 1188-1191. http://dx.doi.org/10.1037/a0029969 


\section{INSATIABILITY}

Galbraith, J. K. (1998). The affluent society (40th Anniversary edition). New York: Houghton Mifflin.

Glenn, S. S., \& Malagodi, E. F. (1991). Process and content in behavioral and cultural phenomena. Behavior and Social Issues, 1(2), 1-14. http://dx.doi.org/10.5210/bsi.v1i2.163

Grant, L. K. (2010). Sustainability: From excess to aesthetics. Behavior and Social Issues, 19, 7-47. http://dx.doi.org/10.5210/bsi.v19i0.2789

Goldberg, M. E., Gorn, G. J., Peracchio, L. A., \& Bamossy, G. (2003). Understanding materialism among youth. Journal of Consumer Psychology, 13, 278-288. http://dx.doi.org/10.1207/S15327663JCP1303_09

Hayden, A. (1999). Sharing the work, sparing the planet: Work time, consumption, \& ecology. Toronto, Canada: Between the Lines.

Herrnstein, R. J. (1970). On the law of effect. Journal of the Experimental Analysis of Behavior, 13, 243-266. http://dx.doi.org/10.1901/jeab.1970.13-243

Holwerda, T. (2009, February 25). Ballmer: Linux bigger competitor than Apple. OS News. Retrieved from http://www.osnews.com/story/21035/Ballmer_Linux.

Jackson, T., Jager, W., \& Stagl, S. (2004). Beyond insatiability: needs theory, consumption and sustainability. ESRC Sustainable Technologies Programme Working Paper Series, (2004/2). Retrieved from http://portal.surrey.ac.uk/pls/portal/docs/PAGE/ENG/RESEARCH/CES/CESRESEARCH/ECOLOGICALECONOMICS/PROJECTS/FBN/BEYONDINSATIABILITY.PDF.

Kanter, J. W., Manos, R. C., Bowe, W. M., Baruch, D. E., Busch, A. M., \& Rusch, L. C. (2010). What is behavioral activation?: A review of the empirical literature. Clinical Psychology Review, 30, 608-620. http://dx.doi.org/10.1016/j.cpr.2010.04.001

Knight, K. W., Rosa, E. A., \& Schor, J. B. (2013). Could working less reduce pressures on the environment? A cross-national panel analysis of OECD countries, 1970-2007. Global Environmental Change, 23, 691-700. http://dx.doi.org/10.1016/j.gloenvcha.2013.02.017

Korten, D. C. (2001). When corporations rule the world ( $2^{\text {nd }}$ Ed.). Bloomfield CN: Kumarian Press.

Krathwohl, D.R., Bloom, B.S., \& Masia, B.B. (1964). Taxonomy of educational objectives: The classification of educational goals. Handbook II: The affective domain. New York: David McKay.

Lakhani, K. R., \& Wolf, R. G. (2005). Why hackers do what they do: Understanding motivation effort in free/open source software projects. In J. Feller, B. Fitzgerald, S. A. Hissam, \& K. R. Lakhani (Eds.) Perspectives on free and open source software (pp. 3-22). Cambridge, Massachusetts: MIT Press. Retrieved from http://flosshub.org/system/files/lakhaniwolf.pdf.

Larson, R. (2000). Toward a psychology of positive youth development. American Psychologist, 55, 170-183. http://dx.doi.org/10.1037/0003-066X.55.1.170

Layard, R. (2003) Has social science a clue?: What is happiness? Are we getting happier? Lionel Robbins memorial lecture series March 3-5, London School of Economics. Retrieved from http://eprints.lse.ac.uk/47425/.

Layard, R. (2005). Happiness: Lessons from a new science. New York: Penguin.

Lekes, N., Joussemet, M., Koestner, R., Taylor, G., Hope, N. H., \& Gingras, I. (2011). Transmitting intrinsic value priorities from mothers to adolescents: The moderating role of a supportive family environment. Child Development Research, 2011. http://dx.doi.org/10.1155/2011/167146

Leonhardt, D. (2008, April 16). Maybe money does buy happiness after all. The New York Times, Retrieved from http://www.nytimes.com/2008/04/16/business/16leonhardt.html?scp=1\&sq=money+doesn $\% 27 \mathrm{t}+$ buy + happines $\underline{s} \& s t=n y t \& \_r=0$.

Lewinsohn, P. (1974). A behavioral approach to depression. In R. J. Friedman, \& M. M. Katz (Eds.), Psychology of depression: Contemporary theory and research (pp. 157-185). Oxford, U.K.: John Wiley \& Sons.

Lovaas, O. I., Freitag, G., Kinder, M. I., Rubenstein, B. D., Schaeffer, B., \& Simmons, J. Q. (1966). Establishment of social reinforcers in two schizophrenic children on the basis of food. Journal of Experimental Child Psychology, 4, 109-125. http://dx.doi.org/10.1016/0022-0965(66)90011-7

Lynch, K. (2010). Carelessness: A hidden doxa of higher education. Arts and Humanities in Higher Education, 9 , 54-67. http://dx.doi.org/10.1177/1474022209350104

Martin, G., \& Pear, J. (2011). Behavior modification: What it is and how to do it. (9th ed.) Upper Saddle River, NJ: Pearson.

Matthews, D. (2013, April 29). Yes, money really can buy happiness. The Washington Post. Retrieved from http://www.washingtonpost.com/blogs/wonkblog/wp/2013/04/29/yes-money-really-can-buy-happiness/.

McEachern, W. A. (2012). Economics: A contemporary introduction (9th ed). Mason, OH: South-Western Centgage Learning. 


\section{GRANT}

McKibben, B. (2007). Deep economy: The wealth of communities and the durable future. New York: Times Books.

Michael, J. (2004). Concepts and principles of behavior analysis. Kalamazoo, MI: Association for Behavior Analysis.

Michaels, F. S. (2011). Monoculture: How one story is changing everything. Vancouver, Canada: Red Clover Press.

Mill, J. S. (1848). Of the stationary state. Retrieved from http://www.panarchy.org/mill/stationary.1848.html.

Moher, C. A., Gould, D. D., Hegg, E., \& Mahoney, A. M. (2008). Non-generalized and generalized conditioned reinforcers: establishment and validation. Behavioral Interventions, 23, 13-38. http://dx.doi.org/10.1002/bin.253

Munoz, S. S. (2008, April 16). It turns out money can buy happiness. The Wall Street Journal. Retrieved from http://blogs.wsj.com/juggle/2008/04/16/it-turns-out-money-can-buy-happiness/.

Norton, B., Costanza, R., \& Bishop, R. C. (1998). The evolution of preferences : Why 'sovereign' preferences may not lead to sustainable policies and what to do about it. Ecological Economics, 24, 193-211. http://dx.doi.org/10.1016/S0921-8009(97)00143-2

O'Barr, W. (2006). Advertising, cultural criticism, and pedagogy: An interview with Sut Jhally. In Sut Jhally (Ed.)., The spectacle of accumulation: Essays in culture, media, \& politics (pp. 1-21). New York: Peter Lang.

Palmer, D. C., \& Donahoe, J. W. (1992). Essentialism and selectionism in cognitive science and behavior analysis. American Psychologist, 47, 1344-1358. http://dx.doi.org/10.1037/0003-066X.47.11.1344

Peterson, C., Park, N., Hall, N., \& Seligman, M. E. (2009). Zest and work. Journal of Organizational Behavior, 30, 161-172. http://dx.doi.org/10.1002/job.584

Pierre, E., \& Oughton, J. (2007). The affective domain: Undiscovered country. College Quarterly, 10(4). Retrieved from http://www.collegequarterly.ca/2007-vol10-num04-fall/pierre-oughton.html.

Premack, D. (1959). Toward empirical behavior laws: I. Positive reinforcement. Psychological Review, 66, $219-233$. http://dx.doi.org/10.1037/h0040891

Putnam, R. D. (2000). Bowling alone: The collapse and revival of American community. New York: Simon and Schuster.

Russell, B. (1930). The conquest of happiness. New York: W. W. Norton.

Russell, B. (1935). In praise of idleness. Retrieved from http://www.zpub.com/notes/idle.html.

Sacks, D. W., Stevenson, B., \& Wolfers, J. (2012). The new stylized facts about income and subjective well-being. Emotion, 12, 1181-1187. http://dx.doi.org/10.1037/a0029873

Sanguinetti, A. (2012). The design of intentional communities: A recycled perspective on sustainable neighborhoods. Behavior and Social Issues, 21, 5-25. http://dx.doi.org/10.5210/bsi.v21i0.3873

Sanne, C. (2002). Willing consumers--Or locked-in? Policies for a sustainable consumption. Ecological Economics, 42, 273-287. http://dx.doi.org/10.1016/S0921-8009(02)00086-1

Schafer, D. P. (2008). Revolution or Renaissance: Making the transition from an economic age to a cultural age. Ottawa, Canada: Ottawa University Press.

Schor, J. B. (1992). The overworked American: The unexpected decline of leisure. New York: Basic Books.

Scitovsky, T. (1977). Can changing consumer tastes save resources? Journal of Cultural Economics, 1(2), 1-12. http://dx.doi.org/10.1007/bf02427545

Scitovsky, T. (1989a). Human desire and economic satisfaction. New York: New York University Press.

Scitovsky, T. (1989b). Subsidies for the arts: The economic argument. In T. Scitovsky (Ed.) Human desire and economic satisfaction (pp. 149-159). New York: New York University Press.

Scitovsky, T. (1992). The joyless economy: The psychology of human satisfaction (Revised ed.). New York: Oxford University Press.

Shechtman, N., DeBarger, A. H., Dornsife, C., Rosier, S., \& Yarnall. L. (2013). Promoting grit, tenacity, and perseverance: Critical factors for success in the 21st Century. Washington, DC: U.S. Department of Education, Office of Educational Technology, Center for Technology in Learning, SRI International. Retrieved from http://pgbovine.net/OET-Draft-Grit-Report-2-17-13.pdf.

Shi, D. E. (1985). The simple life: Plain living and high thinking in American culture. New York: Oxford University Press.

Skinner, B. F. (1953). Science and human behavior. New York: Free Press.

Skinner, B. F. (1974). About behaviorism. Alfred A. Knopf.

Skinner, B. F. (1976). Walden two (Reissued edition). New York: Macmillan.

Stebbins, R. A. (2007). Serious leisure: A perspective for our time. New Brunswick, NJ: Transaction Publishers.

Stearns, P. N. (2006). Consumerism in world history: The global transformation of desire. (2nd ed.). New York: Routledge. 


\section{INSATIABILITY}

Stevenson, B., \& Wolfers, J. (2008). Economic growth and happiness: Reassessing the Easterlin paradox. Brookings Papers on Economic Activity, Economic Studies Program, The Brookings Institution, 39, 1-102. Retrieved from http://www.nber.org/papers/w14282.

Stevenson, B., \& Wolfers, J. (2013). Subjective well-being and income: Is there any evidence of satiation?, CESifo Working Paper, No. 4222. Retrieved from http://hdl.handle.net/10419/72663.

Stiglitz, J. E. (2010). Toward a general theory of consumerism: Reflections on Keynes's Economic possibilities for our grandchildren. In L. Pecchi \& G. Piga (Eds.) Revisiting Keynes: Economic possibilities for our grandchildren (pp. 42-85). Cambridge, MA: The MIT Press.

Stiglitz, J. E. (2012). The price of inequality. New York: W. W. Norton.

Swim, J., Clayton, S., Doherty, T., Gifford, R., Howard, G., Reser, J., ...Weber, E. (2010). Psychology and global climate change: Addressing a multi-faceted phenomenon and set of challenges. Retrieved from http://www.apa.org/science/about/publications/climate-change.aspx.

Thoreau. H. D. (1854/1995). Walden; or, life in the woods. New York: Dover.

Warren, V. L., \& Cairns, R. B. (1972). Social reinforcement satiation: An outcome of frequency or ambiguity? Journal of Experimental Child Psychology, 13, 249-260. http://dx.doi.org/10.1016/0022-0965(72)90088-4

Wetzsteon, R. (2002). Republic of dreams Greenwich Village: The American Bohemia, 1910-1960. New York: Simon \& Schuster.

Wilkinson, R., \& Pickett, K. (2010). The spirit level: Why equality is better for everyone. London, UK: Penguin. Wolf, M. M. (1978). Social validity: The case for subjective measurement or how applied behavior analysis is finding its heart. Journal of Applied Behavior Analysis, 11, 203-214. http://dx.doi.org/10.1901/jaba.1978.11203 